\title{
Immunohistochemical Expression of Heat Shock Protein27 in the Mouse Dental Pulp after Immediate Teeth Separation
}

\author{
S. Saito ${ }^{1}$, K. Nakano 2 , A. Nabeyama ${ }^{2,4}$, M. Sato ${ }^{4}$, N. Okafuji ${ }^{3}$, A. Yamamoto ${ }^{1,4}$, E. Kasahara ${ }^{4}$ and \\ T. Kawakami ${ }^{2}$

\footnotetext{
${ }^{1}$ Oral Health Analysis Unit, Matsumoto Dental University Graduate School of Oral Medicine, Shiojiri, Japan

${ }^{2}$ Hard Tissue Pathology Unit, Matsumoto Dental University Graduate School of Oral Medicine, Shiojiri, Japan

${ }^{3}$ Clinical Evaluation Unit, Matsumoto Dental University Graduate School of Oral Medicine, Shiojiri, Japan
} \\ ${ }^{4}$ Department of Endodontics and Operative Dentistry, Matsumoto Dental University School of Dentistry, Shiojiri, Japan
}

\begin{abstract}
Aim: After immediate teeth separation, expression of HSP27 in the mouse dental pulp was examined. Immunohistochemistry was performed to examine the incidence of HSP27 expression.

Materials and methods: A total of 36 8-week-old ddY mice were used as experimental subjects and a wedge was inserted in between maxillary right molars. The wedge was removed $30 \mathrm{~min}$ or $3 \mathrm{~h}$ after insertion. Animals were immediately sacrificed after the removal of wedge or until 1 week later and serial sections from paraffin-embedded tissues were prepared. Immunohistochemistry was carried out to examine the expression of HSP27. The untreated side served as the control.

Results: In the control group, the endothelial cells and some pulp fibroblasts weakly expressed HSP27 suggesting that the expression is due to mechanical stress brought about by physiological masticatory force and pressure from the tongue. In both $30 \mathrm{~min}$ and $3 \mathrm{~h} \mathrm{ex-}$ perimental groups, HSP27 expression was highest at $24 \mathrm{~h}$ after wedge removal and the expression remained the same or started to decrease thereafter. The expression decreased at the same level as that of the control group 1 week after wedge removal.

Conclusion: HSP27 may serve as an indicator of stimulus strong enough to show its expression.
\end{abstract}

Key words: Heat shock protein27, Mechanical stress, Immediate teeth separation, Dental pulp

\section{INTRODUCTION}

During conservative dental treatment and restoration of contact area using composite filling, immediate teeth separation may be necessary by using a wedge or sometimes a separator. Even during food impaction, teeth are separated inducing mechanical stress. Stress does not directly act as pressure or traction on periodontal ligament. Mechanical stress affects the pulp and travels to the apical part going to the lateral branch and then to the periodontal tissues. In recent years, HSP25 expression has been reported in dental pulp after injury induced by cavity preparation and tooth replantation [1].
Previously, a cytotoxic protein known as heat shock protein (HSP) has been reported to occur as a major protein observed in various tissues and organs due to mechanical irritation or stress [2]. HSP is not only induced by heat shock but also by ischemia, various pathological changes like inflammation and infection; physical stress such as radiation, light, enzymes, ions; heavy metals like arsenic, arsenite, chemicals and variety of amino acid derivatives like ethanol and reactive oxygen species [3, 4]. HSPs have been associated in cell damage, defense and repair and are thought to be involved in controlling cell function [5-7].

HSP27 has role in suppression of apoptosis, control of protein expression, chaperone activity by binding to nascent protein, cell development and cell differentiation. It is also involved in cell signal transduction [8-12]. However, the dynamics and its role in pulp tissue in regulating cellular response to cytotoxic stimuli during experimental teeth separation have not been investigated. Shigehara et al. [13] reported HSP70 mRNA expression in dental pulp after orthodontic teeth movement and mentioned that mechanical stress is one of the factors in the expression of HSP70. Muraoka et al. [14] histologically observed HSP27 expression in pulp tissue and mentioned that biomechanical stress in periodontal ligament induced the expression and incidence of HSP27. The changes in the expression of HSP27 in the pulp in the control group were thought to be due to mechanical stress by orthodontic force. Thus, similar expression changes in HSP27 were observed in this research when teeth were separated using a wedge.

In this study, a detailed pathological investigation focused on the immunohistochemical expression of HSP27 in pulp cells after applying mechanical stress caused by teeth separation on experimental laboratory animals.

\section{MATERials AND METHOds}

\section{1) Experimental Animals}

A total of 368 -week-old ddY mice weighing $35 \pm 5 \mathrm{~g}$ (30-40g) were purchased from Japan SLC Inc (Hamamatsu, Japan). The mice were kept in an air-condi- 
tioned room with controlled temperature at $24 \pm 1{ }^{\circ} \mathrm{C}$. Animals were reared in paper-lined plastic cages ( $\mathrm{Pa}$ per clean: Peparlet Co., Ltd, Shizuoka, Japan). Mice were freely fed with solid feeds (Picolab Rodent Diet 20: Japan SLC Inc, Hamamatsu, Japan) and water.

\section{2) Experimental Method}

Prior to the experiment, the mice were subjected to inhalation anesthesia with isoflurane (ISOFLU: Dainippon Sumitomo Pharma Co. Animal Science, Osaka, Japan) and gas air mixture (4.0\% pre-concentration of anesthesia). The experiments were performed under a stable anesthetic concentration with adjustable constant flow rate of gas anesthesia system for small laboratory animal (DS Pharma Biomedical Co. Ltd, Laboratory products, Osaka, Japan). After induction of anesthesia, the upper body of the mouse was fixed in a homemade bench. Isoflurance inhalation anesthesia was allowed to flow and maintained during the experiment by inserting a suction hole in the nose from time to time (1.0\% maintenance concentration). In order to keep the mouth open during the experiment, the jaw was fixed with a thread tied on the upper incisor from the top of the bench and the lower jaw was hung and fixed on the lower bench with a thread tied on the lower incisors. Then after a wedge (Anatomical WIZARD WEDGES: Water Pik, Inc. Ft. Collins, Colorado, U.S.A.) was inserted in between maxillary molars. The teeth included in the sections are the following: maxillary first molar (M1), maxillary second molar (M2), maxillary third molar (M3) where M1 has 3 roots, M2 has 3 roots and M3 has 2 to 3 roots (Fig. 1-a). The wedge was inserted in between the right maxillary first (M1) and second (M2) molars. The experimental groups were first divided into 2 groups: $30 \mathrm{~min}$ and 3 $\mathrm{h}$, the time where in the wedge was left inserted in between teeth (separation time). Then, the groups were further divided 0 min, 3 h, 9 h, 24 h, 3 days, 1 week as the time after the removal of the wedge until the mouse was sacrificed for histological examination. A total of 12 experimental groups were formed. The number of samples in each group is shown on Table 1. When the duration of anesthesia has lapsed after each experiment, isoflurane inhalation was similarly given. The tissue sample excised consists of a portion of periodontal tissue of the maxillary molars.

For the control group, the left maxillary tissue of the same subject (opposite untreated side) was used. In this study, the largest tooth closest to the insertion of the wedge would be considered to receive the largest mechanical stress. Although the maxillary second molar is the largest tooth, observation was done on the distal part of the buccal root of the maxillary first molar (Fig. 1-b). The ethics committee on labora- tory animals of Matsumoto University approved the study.

\section{Histological Examination}

The maxillary bone together with maxillary molars and periodontal tissues were removed and immediately fixed in $4 \%$ paraformaldehyde in $0.05 \mathrm{M}$ phosphate buffer for $24 \mathrm{~h}$. After fixation, the specimens were demineralized in 10\% EDTA solution for 3 weeks. Tissues were embedded in paraffin and serial horizontal sections of $4 \mu \mathrm{m}$ thickness were cut and subjected to histological and immuhistochemical analyses.

\section{IMMUNOHISTOCHEMISTRY}

Prior to staining, the slides were deparaffinized in xylene and pretreated in incubator at $60^{\circ} \mathrm{C}$ for $30 \mathrm{~min}$. Immunohistochemistry was done with Dako Envision + Kit-K4006 (Dako Glostrup, Denmark). The primary antibody used was mouse monoclonal HSP27 (HSP27 [SPM252]: sc-65567, Santa Cruz Biotechnology, Inc, CA, USA) with a dilution of 1:5000. Slides were counterstained with hematoxylin. For negative control, PBS was used instead of primary antibody.

\section{RESULTS}

\section{Histological Examination}

\section{Control group}

Pulp tissues of the left maxillary molars vary in each specimen with an average length of $26 \mu \mathrm{m}$ and width of $22 \mu \mathrm{m}$. The root canal dentin layer is partly lined by odontoblasts, some are in contact with the dentin and some overlap each other. Fibroblasts are present in the center of the pulp. Capillaries are present in between pulp fibroblasts and in the odontoblast layer.

\section{Experimental group}

In 30 min group, hemorrhage was noted but no significant change was observed when compared with the control group. In $3 \mathrm{~h}$ group, congestion is generally evident causing bleeding.

\section{IMMUNOHISTOCHEMISTRY}

\section{Control group}

HSP27 is weakly expressed in the cytoplasm of endothelial cells in the odontoblast layer (Fig. 2).

\section{Experimental 30 min group (Fig. 3, a-d)} Immediately after removing the wedge ( 0 min), HSP27 expression in pulp fibroblasts and in the cytoplasm of endothelial cells located in the odontoblast layer remained weak similar as in the control group (Fig. 3-a).

Table 1. Experimental Periods and Number of Specimens.

\begin{tabular}{lcccccccc}
\hline & & 0min & 3hrs & 9hrs & 24hrs & 3days & 1week & Total \\
\hline Experimental & 30min & 3 & 3 & 3 & 3 & 3 & 3 & 18 \\
& 3hrs & 3 & 3 & 3 & 3 & 3 & 3 & 18 \\
Control & & & & & & & & 6 \\
\hline
\end{tabular}


In $3 \mathrm{~h}$ group, HSP27 expression in the cytoplasm of endothelial cells became stronger (Fig. 3-b). In $9 \mathrm{~h}$ group, HSP27 became stronger and is expressed in the cytoplasm of endothelial cells as well as in some fibroblasts in the coronal pulp. In $24 \mathrm{~h}$ group, HSP27 expression remained the same with $9 \mathrm{~h}$ group (Fig. 3c). In 3 days group, HSP27 expression in the odontoblast layer can still be observed but a decrease in expression is evident. In 1 week group, HSP27 further decreased with no difference with the control group (Fig. 4d).

Experimental 3 h group (Figs. 4, a-d; 5, a-d)

Immediately after removing the wedge, HSP27 was expressed by capillary endothelial cells surrounding the pulp and fibroblasts in the pulp (Fig. 4-a). In $3 \mathrm{~h}$ group, HSP27 was strongly expressed in the odontoblast layer (Fig. 5-a, b), cytoplasm of capillary endothelial cells surrounding the resident pulp cells (Fig. 5c), cytoplasm of pulp fibroblasts (Fig. 5-d) throughout the pulp (Fig. 5-b; 5-d). In $9 \mathrm{~h}$ group, expression was stronger in the odontoblast layer, capillary endothelial cells of resident pulp cells and pulp fibroblasts. In 24 h group, HSP27 expression increased in the odontoblast layer, capillary endothelial cells of resident pulp cells, pulp fibroblasts (Fig. 4-c). In 3 days group, HSP27 can still be uniformly observed in the odontoblast layer, capillary endothelial cells of resident pulp cells, pulp fibroblasts but had weakened considerably. In 1 week group, HSP27 in the odontoblast layer, capillary endothelial cells of resident pulp cells, pulp fibroblast remained weak (Fig. 4-d).

\section{Discussion}

Qualitative observation on immunohistochemical expression of HSP27 using mice as experimental subjects was performed in this study. The number of animals used is large enough so that the difference in immune response will not be due to individual differences. Two groups were made and further divided into 6 groups consisting of 3 mice per group for a total of 36 mice.

Base on preliminary results, the buccal root of the right maxillary first molar would be the most appropriate area for observation. This is because when the coronal pulp and radicular pulp showed the same HSP27 staining condition after subjecting to mechanical stress observed in longitudinal section. Thus, it seemed to be the most affected compared to the other 2 roots (Fig. 2).

In addition, the 30 min separation time is the maximum separation time use in dental clinical settings. Also, each group provided 3 hours of time and about 6 times more to induce a more severe stress. The specimens were prepared immediately after the shortest separation time or from $3 \mathrm{~h}$ to 1 week to determine the prevalence of stress after removal of the wedge.

Separation of teeth during dental treatment is converted to mechanical stress that directly affects the periodontal tissues [14]. It can also be understood that the damage can act as a stimulus to the dental pulp in the same manner. In other words, some cytotoxic substances may cause nerve irritation through the vessel relative to the movement in the apical foramen. The stimulus is thought to also take place in the lateral branch. However, in our search for literatures, no study has been conducted so far examining the expression of HSPs during cytotoxic changes in pulp cells. Sens et al. [15] reported the expression of HSP in odontoblasts, odontoblast's processes (dentinal fibers), dental pulp fibroblasts, endothelial cells, and vascular smooth muscle cells in human 3rd molars. Further, Tate et al. [16] and Suzuki et al. [17] verified the expression of HSP in dental pulp cells after experimental cavity preparation by laser ablation. Moreover, Matsuzaki et al. [18] reported an increased in mRNA levels of HSP27 in the pulp. However, the expression of HSP27 in dental pulp cells after teeth separation has not been investigated. However, HSP27 expression has been implicated in the expression of Runx 2 in dental pulp under mechanical stress in orthodontic researches [19, 20].

Recently, it is well known that homeostasis and expression of HSP27 can be stimulated by various injuries. HSPs are protein acquired for survival under harsh environment in the cell induced by non-physiological stimuli, as molecular chaperone [21] with antiapoptotic feature which allows cell to escape from death $[6,7,11]$. In addition, many cells in response to stress and inhibit protein denaturation by repairing denatured proteins express HSPs. Previous in vitro and in vivo experiments found that HSP is a protein widely distributed in intracellular equilibrium, constitutively expressed under stress condition and actually even in unstressed condition, cell differentiation, proliferation, survival and essential various cellular functions such as maintenance of protein $[7,21]$.

HSPs like HSP70 and HSP90 are high molecular weight HSP temporarily attached to the immature state of protein known to act as a molecular chaperone with the ability to assist and mature protein folding and to mediate the meeting of polypeptides [22]. The speculation that low molecular weight HSPs function as molecular chaperone in cells is not clear [23].

This investigation on HSP27 was initially discovered as an inhibitor of actin polymerization [24]. Thereafter, high levels of HSP27 became known to be present at high levels in vascular smooth muscle cells in unstimulated conditions. From this, HSP27 is believed to have some physiologic role in vascular cells [25].

First, the dental pulp of the control group has always shown weak positive reaction to HSP27. Similar results to Nakano et al. [20] have been observed and it is presumed that the response is due to the load from physiological and biomechanical masticatory force and tongue pressure. In addition, HSP27 observed in the control group in pulp fibroblasts is weak and is mainly expressed by vascular endothelial cells. This expression was noted early during the experiment indicating that HSP27 plays a physiological role in vascular system [25]. In the experimental group with $30 \mathrm{~min}$ separation of teeth, strong HSP27 expression was observed in vascular endothelial cells as well as in some pulp fibroblasts. Also, this expression reached its maximum after $24 \mathrm{~h}$ and then gradually decreased until the expression is the same as the control group. This is due to the stress from separation of teeth, 


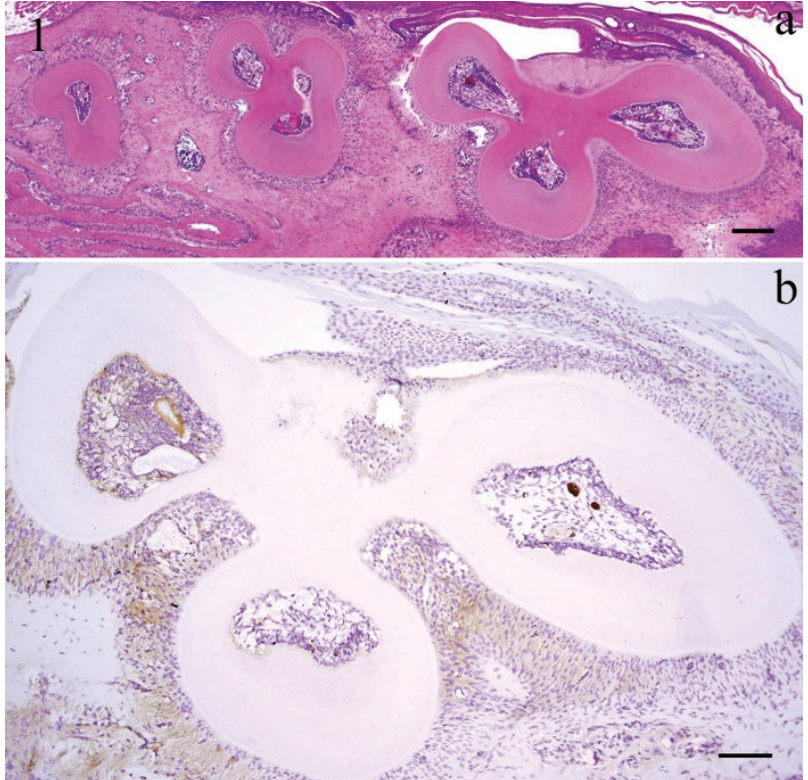

Fig. 1. Histopathological view of the horizontal section of a

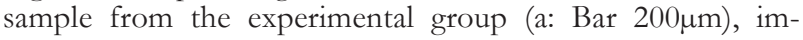
munohistochemical staining profile of HSP27 in the 1st mo-

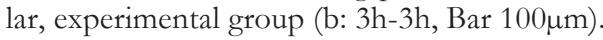

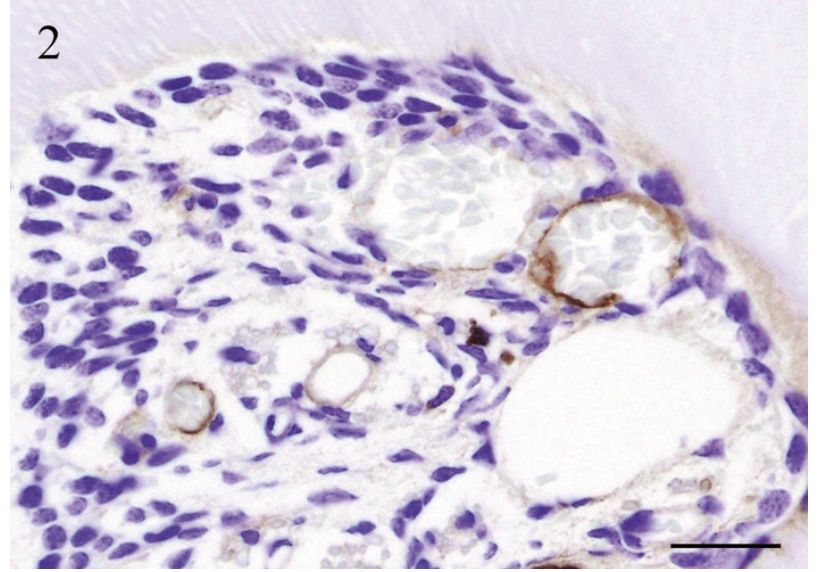

Fig. 2. HSP27 positive staining appeared in some endothelial

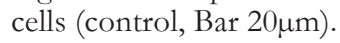

Fig. 4. The positive reactions appeared in almost all dental pulp tissue cells (a: $3 \mathrm{~h}-0 \mathrm{~m}$, Bar $20 \mu \mathrm{m}$ ); staining reaction become strong (b: $3 \mathrm{~h}-3 \mathrm{~h}, \mathrm{Bar} 20 \mu \mathrm{m})$, the strong positive reactions are observed in pulp cells (c: $3 \mathrm{~h}-24 \mathrm{~h}$, Bar $20 \mu \mathrm{m})$, strong positive reaction in the pulp cells (d: $3 \mathrm{~h}-1 \mathrm{w}$, Bar $20 \mu \mathrm{m})$.

Fig. 5. Immunohistochemical staining in the odontoblasts layers, positively stained small vessels are noted (a, b: $3 \mathrm{~h}-3 \mathrm{~h}$, Bar $10 \mu \mathrm{m})$. The experimental dental pulp shows strong positive reactions in endothelial cells (c: $3 \mathrm{~h}-9 \mathrm{~h}$, Bar $10 \mu \mathrm{m})$, weak positive staining in some dental pulp fibroblasts (d: $3 \mathrm{~h}-9 \mathrm{~h}$, Bar 10 $\mu \mathrm{m})$ are noted in the pulp chamber.
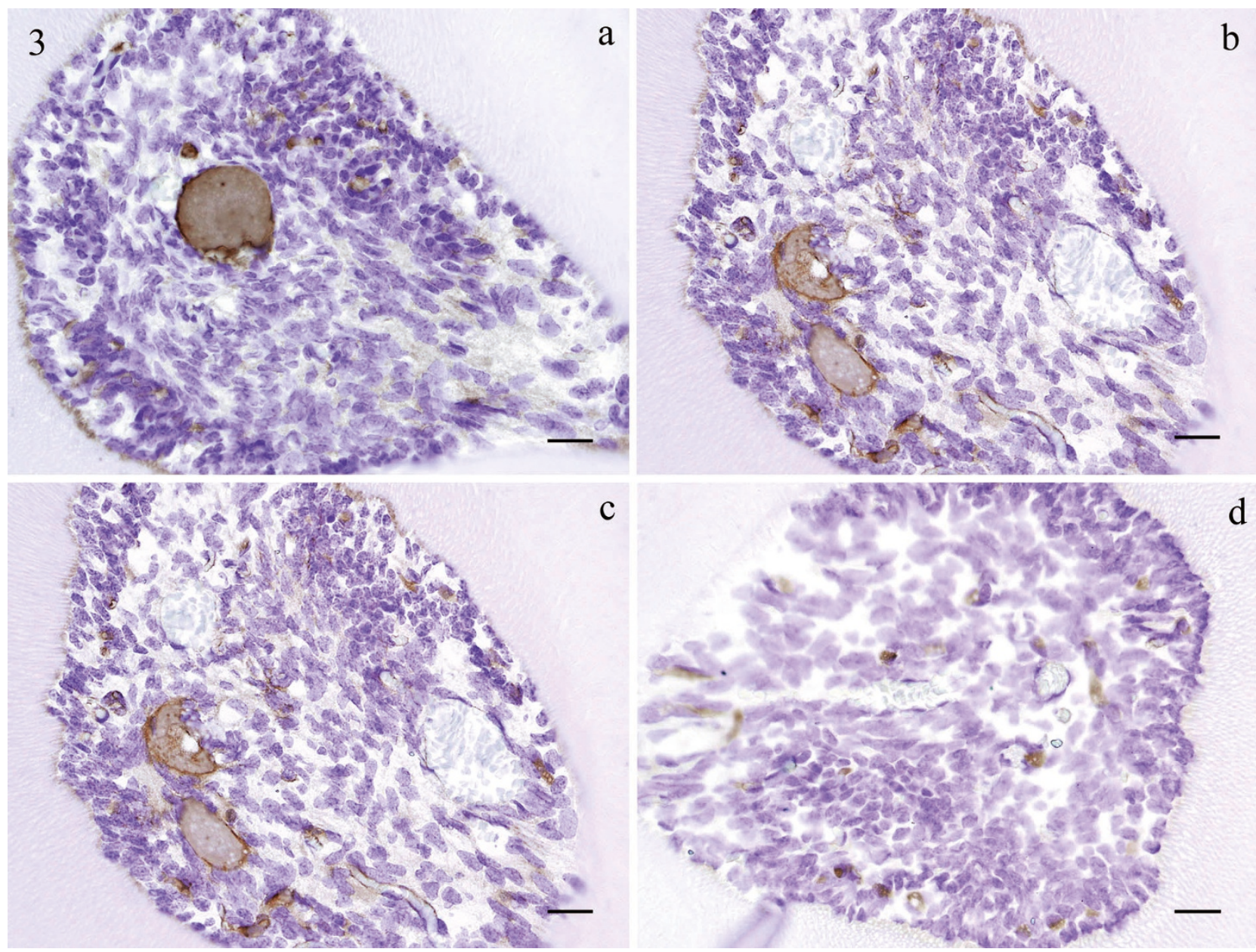

Fig. 3. Weakly positive staining present in some dental pulp cells (a: $30 \mathrm{~m}-0 \mathrm{~m}$, Bar $20 \mu \mathrm{m}$ ), pulp fibroblasts and capillaries (b: $30 \mathrm{~m}-3 \mathrm{~h}, \mathrm{Bar} 20 \mu \mathrm{m})$. Almost all pulp cells, including pulpal fibroblasts and endothelial cells show strong positive expression (c: $30 \mathrm{~m}-24 \mathrm{~h}$, Bar $20 \mu \mathrm{m})$ and weakly positive in some cells (d: $30 \mathrm{~m}-1 \mathrm{w}$, Bar $20 \mu \mathrm{m}$ ). 
4

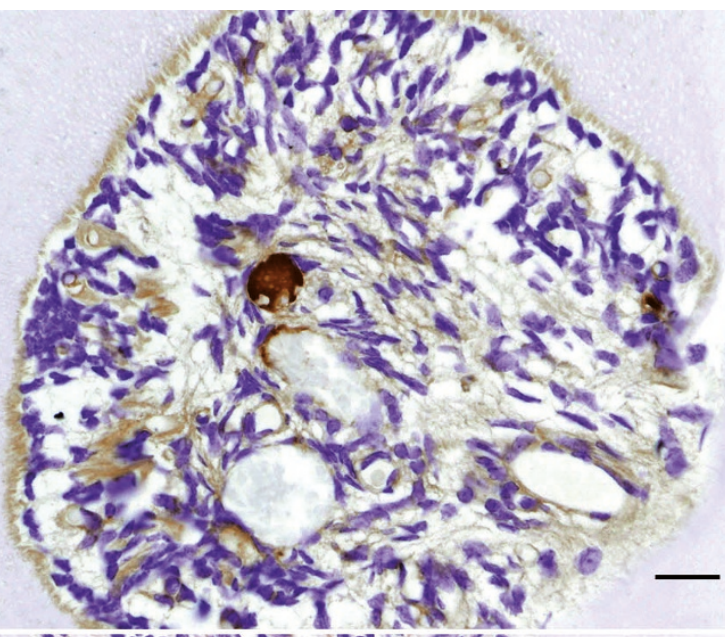

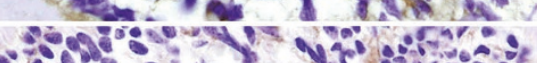

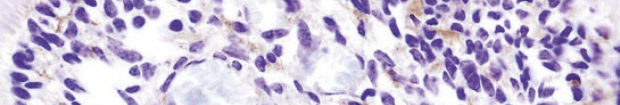

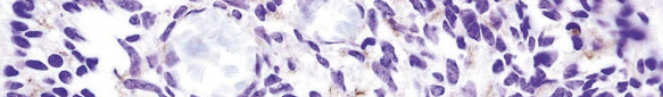

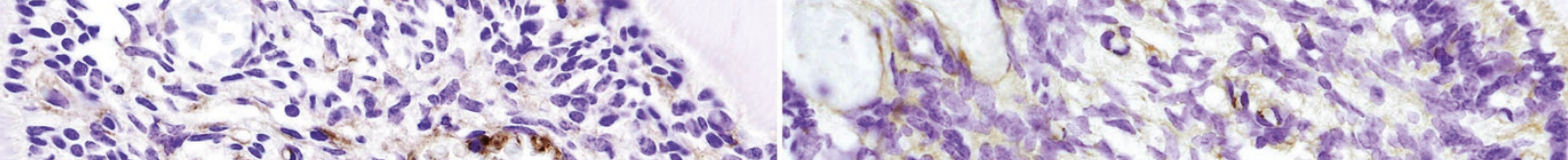

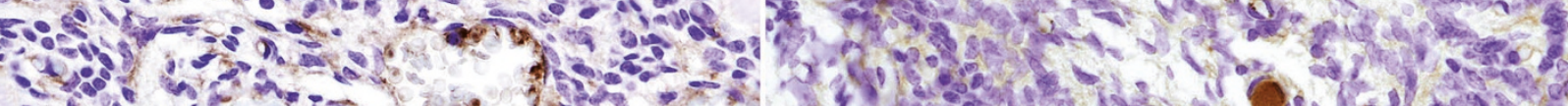

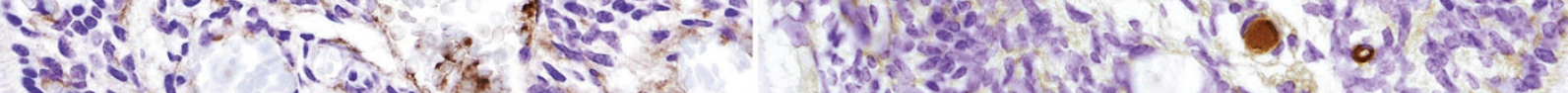

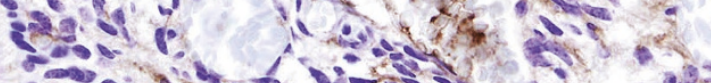

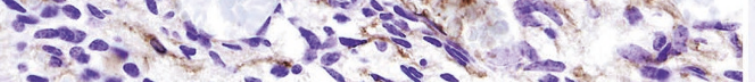

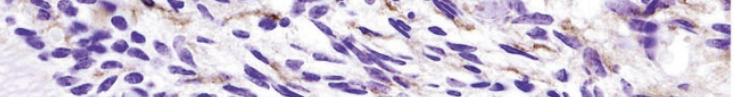

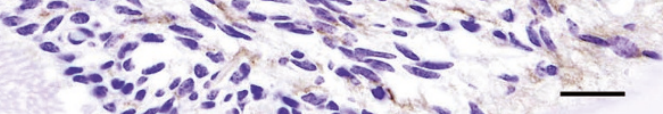

a

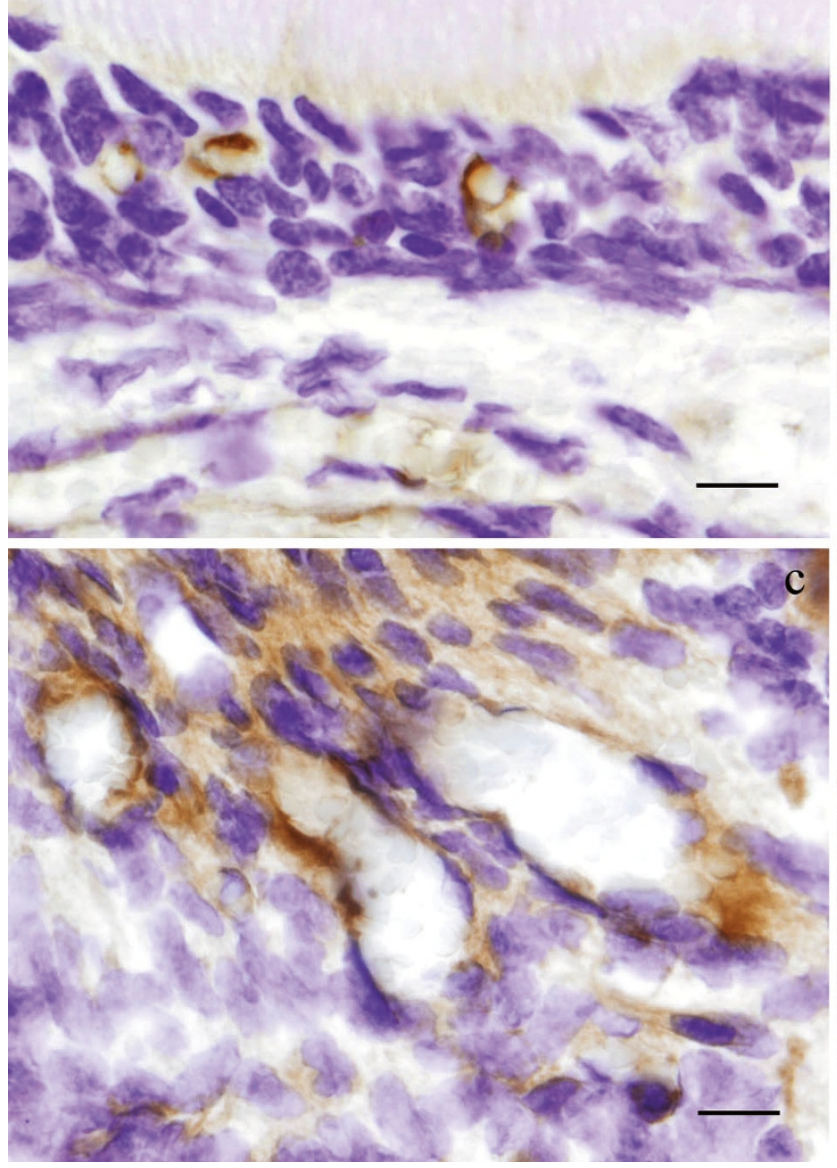

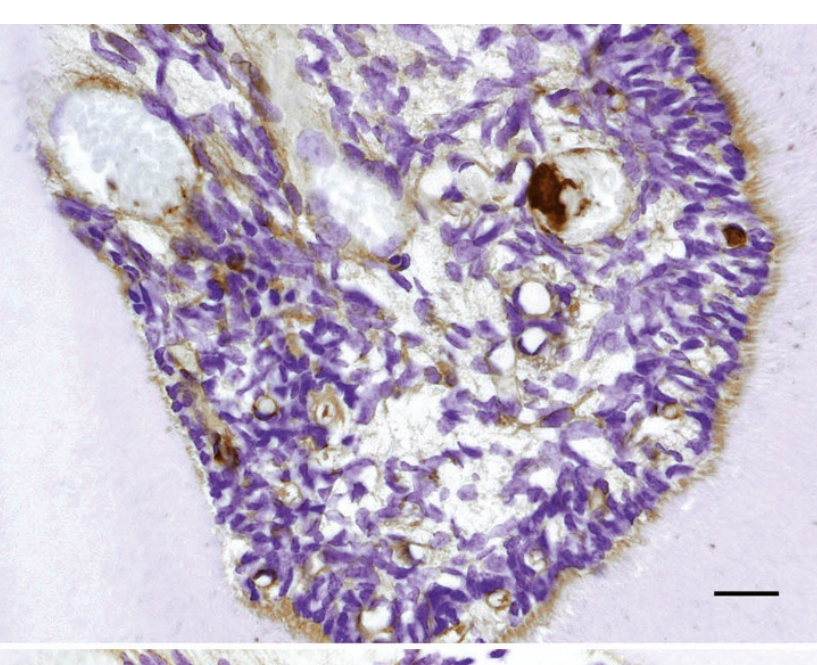

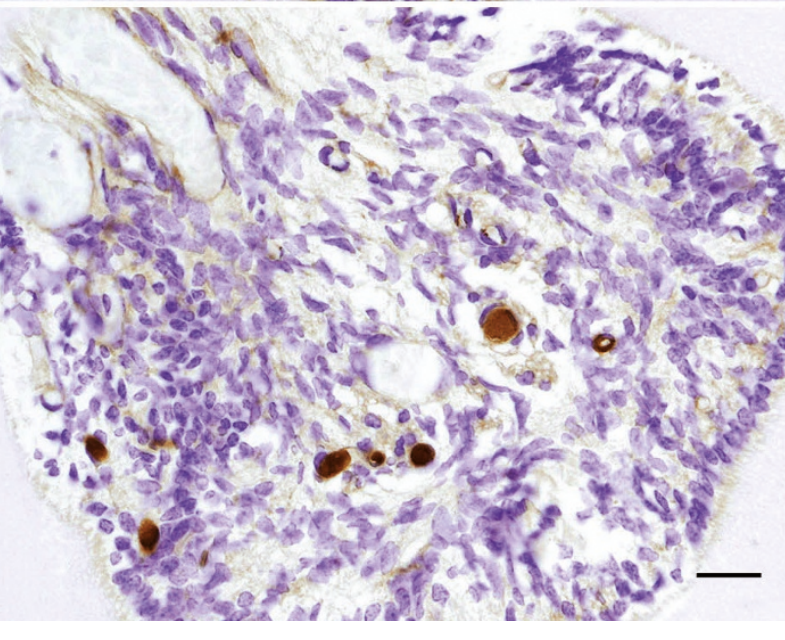
b

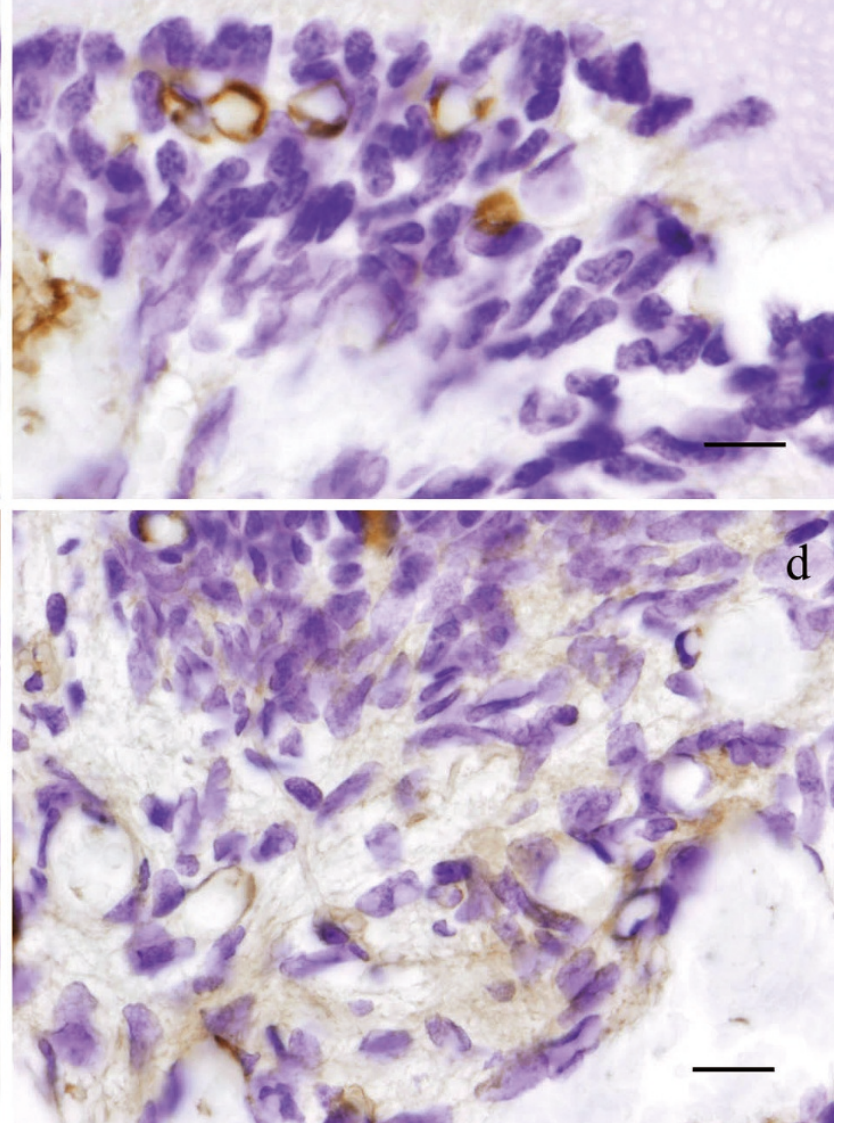


which stimulated some endothelial cells and their reaction was to express HSP27. This may also be their way to recover from stress. However, the expression was reduced to the same level as that of the control group after a week suggesting that the injury or the stimulus was not that strong. For this, even if the $3 \mathrm{~h}$ group is compared to 6 -fold stimulation over time, a similar trend was observed. Thus, separation of teeth creates a strong stimulus after about 1 week as indicated by the expression of HSP27 but the injury is not that destructive enough to the pulp.

\section{CONCLUSION}

Immunohistochemistry was performed to examine the incidence of HSP27 expression. In the experimental groups, HSP27 expression was highest at $24 \mathrm{~h}$ after wedge removal and the expression remained the same or started to decrease thereafter. The expression decreased at the same level as that of the control group 1 week after wedge removal. Thus, HSP27 may serve as an indicator of stimulus strong enough to show its expression.

\section{REFERENCES}

1. Nakakura-Ohshima K, Watanabe J, Kenmotsu S and Ohshima H. Possible role of immunocompetent cells and the expression of heat shock protein-25 in the process of pulpal regeneration after tooth injury in rat molars. J Electron Microsc (Tokyo) 2003; 52(6): 581-591.

2. Schlesinger MJ. Heat shock proteins. J Biol Chem 1990; 265: 12111-12114.

3. Maeda T, Kameda T and Kameda A. Loading of continuously applied compressive force enhances production of heat shock protein 60,70 and 90 in human periodontal ligament-derived fibroblast-like cells. J Jpn Orthod Soc 1997; 56: 296-302.

4. Okazaki M, Shimizu Y, Chiba M and Mitani H. Expression of heat shock proteins induced by cyclical stretching stress in human periodontal ligament fibroblasts. Tohoku Univ Dent J 2000; 19: 108-115.

5. Craig EA, Weissman JS and Horwich AL. Heat shock proteins and molecular chaperones: mediatora of protein conformation and turnover in the cell. Cell 1994; 78: 365372.

6. Arrigo AP and Landry J. Expression and function of the low molecular weight heat shock proteins. In : The biology of heat shock proteins and molecular chaperones. Morimoto RI, Tissieres A, Georgopoulos C, eds, Cold Spring Harbor Laboratory Press, 1994; Plainview, pp335-373.

7. Lindquist $S$ and Craig EA: The heat-shock proteins. Annu Rev Genet 1988; 22: 631-677.

8. Kim KK, Kim R and Kim S. Crystal structure of a small heat shock protein. Nature 1998; 394:595-599.

9. Van Montfort R, Slingsby C and Vierling E. Structure and function of the small heat shock protein/alpha-crystallin family of molecular chaperones. Adv Protein Chem 2001; 59: 105-156.

10. Gusev NB, Bogatcheva NV and Marston SB. Structure and properties of small heat shock proteins (sHsp) and their interaction with cytoskeleton proteins. Biochemistry (Mosc) 2002; 67: 511-519.

11. Sarto C, Binz PA and Mocarelli P. Heat shock proteins in human cancer. Electrophoresis 2000; 21: 1218-1226.

12. Ritossa F. A new puffing pattern induced by temperature shock and DNP in Drosofira. Experientia 1962;18:571-573.
13. Shigehara S, Matsuzaki K and Inoue T. Morphohistological change and expression of HSP70, osteopontin and osteocalcin mRNAs in rat dental pulpcells with orthodontic tooth movement. Bull Tokyo Dent Coll 206; 47: 117-124.

14. Muraoka R, Nakano K, Kurihara S, Yamada K and Kawakami T. Immunohistochemical expression of heat shock proteins in the mouse periodontal tissues due to orthodontic mechanical stress. Eur J Med Res 2010; 15: 475-482.

15. Sens DA, McGuirt JP, Khan W, Todd JH and Howell RM. Expression of heat shock protein 27 in adult human third molar dental pulp. J Oral Pathol Med 1996; 25: 382387.

16. Tate Y, Yoshiba K, Yoshiba N, Iwaku M, Okiji T and Ohshima H. Odontoblast responses to GaAlAs laser irradiation in rat molars: an experimental study using heatshock protein-25 immunohistochemistry. Eur J Oral Sci 2006; 114: 50-57.

17. Suzuki T, Nomura S, Maeda T and Ohshima H. An immunocytochemical study of pulpal responses to cavity preparation by laser ablation in rat molars by using antibodies to heat shock protein(HSP) 25 and class MHC antigen. Cell Tissue Res 2004; 315: 311-319.

18. Matsuzaka K, Muramatsu T, Katakura A, Ishihara K, Hashimoto S, Yoshinari M, Endo T, Tazaki M, Shintani $\mathrm{M}$, Sato $\mathrm{Y}$ and Inoue T. Changes in the homeostatic mechanism of dental pulp with age: expression of the core-binding factor alpha-1, dentin sialoprotein, vascular endothelial growth factor, and heat shock protein 27 messenger RNAs. 2008; J Endod 34: 818-821.

19. Nakano K, Muraoka R, Tomida M, Matsuura S, Okafuji N, Siar CH and Kawakami T. Expression of HSP in Dental Root Pulp Cells due to Experimental Orthodontic Mechanical Stress. J Hard Tissue Biol 2009; 18: 127-130.

20. Nakano K, Muraoka R, Tomida M, Matsuura S, Okafuji N, Siar CH and Kawakami T. Possibility of Odontoblasts Activity Up-Regulation due to Orthodontic Mechanical Stress in Mice. J Hard Tissue Biol 2010; 19: 13-16.

21. Hratl FU. Molecular chaperone in cellular protein folding. Nature 1996; 381: 571-579.

22. Gething MJ and Sambrook J: Protein folding in the cell. Nature 1992; 355: 33-44.

23. Benndorf R, Hayess K, Ryazantsev S, Wieske M, Behlke J and Lutsch G. Phosphorylation and supermolecular organization of murine small heat shock protein HSP25 abolish its actin polymerization-inhibiting activity. J Biol Chem 1994; 269: 20780-20784.

24. Miron T, Vancompernolle K, Vandekerckhove J, Wilchek $\mathrm{M}$ and Geiger B: A $25-\mathrm{kDa}$ inhibitor of actin polymerization is a low molecular mass heat shock protein. J Cell Biol 1991; 114: 255-261.

25. Inaguma Y, Goto S, Shinohara H, Hasegawa K, Ohshima $\mathrm{K}$ and Kato K. Physiological and pathological changes in levels of two small stress proteins, HSP27 and B-crystallin, in rat hind limb muscles. J Biochem 1993; 114: 378384.

Received: May 31, 2011 / Accepted: June 8, 2011

Address for Correspondence:

Toshiyuki Kawakami, PhD, Professor,

Hard Tissue Pathology Unit,

Matsumoto Dental University

Graduate School of Oral Medicine,

1780 Hirooka-Gobara,

Shiojiri, 399-0781 Japan

Phone: +81-263-51-2035

Fax: +81-263-51-2035

E-mail: kawakami@po.mdu.ac.jp 